\title{
Delayed Splenic Pseudoaneurysm Formation after Angioembolization
}

\author{
Chan Yong Park, M.D.
}

Department of Trauma Surgery, Pusan National University Hospital, Busan, Korea
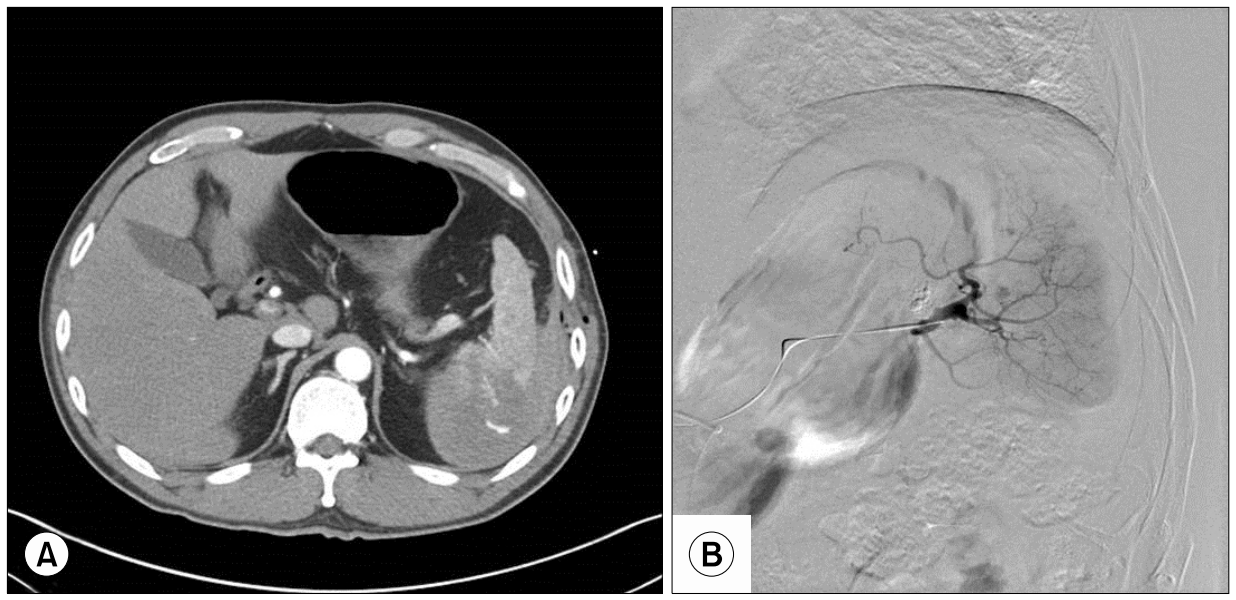

Fig. 1. Computed tomography scan and angiographic images obtained upon admission: (A) Perisplenic contrast blush can be observed. (B) Embolization was performed using gelfoam.

A 48-year-old man experienced blunt abdominal trauma after falling from a height of 7 meters. His systolic blood pressure upon arrival was $120 \mathrm{mmHg}$, and heart rate was 95 beats per min. Abdominal computed tomography (CT) upon admission revealed contrast leakage from a splenic injury (grade 3) (Fig. 1A). Emergency angiography and embolization were performed using gelfoam (Fig. 1B). CT, repeated 7 days after his trauma revealed a pseudoaneurysm (Fig. 2A).

Received June 5, 2018,

Accepted September 19, 2018

Correspondence to: Chan Yong Park, M.D. Department of Trauma Surgery, Pusan

National University Hospital, 179

Gudeok-ro, Seo-gu, Busan 49241, Korea

Tel: +82-51-240-7369, Fax: +82-51-240-7719,

E-mail: traumawkuh@gmail.com

ORCID:

http://orcid.org/0000-0002-5111-3270

Chan Yong Park's current affiliation:

Department of Trauma Surgery,

Wonkwang University Hospital, 895

Muwang-ro, Iksan 54538, Korea
Angioembolization was performed to prevent bleeding from the pseudoaneurysm (Fig. 2B). CT performed a week later revealed no pseudoaneurysm. The patient recovered well and was discharged home There is a lack of evidence regarding the optimal period/frequency of performing CT follow-up after angioembolization for splenic injuries $[1,2]$. Our present case indicates that close follow-up including CT is warranted in patients undergoing angioembolization to monitor for delayed pseudoaneurysm formation.

\section{Conflicts of Interest}

No potential conflict of interest relevant to this article was reported.

Copyright (C) 2018 by Korean Society of Acute Care Surgery

(c) This is an Open Access article distributed under the terms of the Creative Commons Attribution Non-Commercial License (http://creativecommons.org/licenses/by-nc/4.0) which permits unrestricted non-commercial use, distribution, and reproduction in any medium, provided the original work is properly cited. 

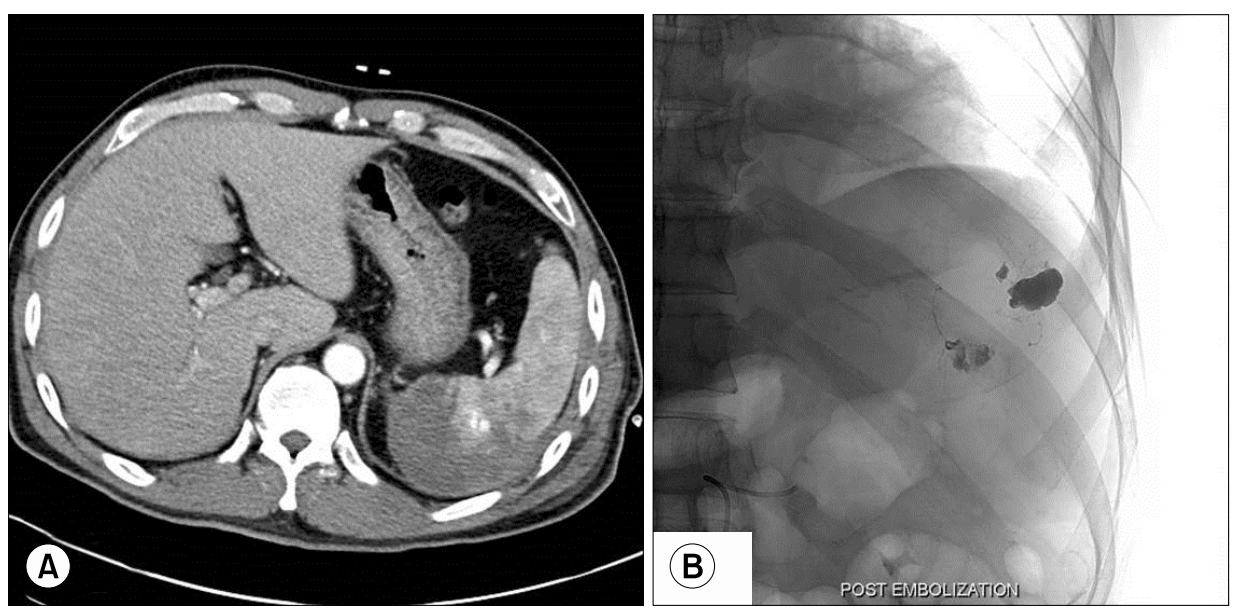

Fig. 2. Follow-up computed tomography scan and angiographic images obtained on the 7th day of hospitalization: (A) A pseudoaneurysm of the spleen can be identified. (B) Re-embolization of the pseudoaneurysm was performed.

\section{References}

1. Stassen NA, Bhullar I, Cheng JD, Crandall ML, Friese RS, Guillamondegui OD, et al. Selective nonoperative management of blunt splenic injury: an Eastern association for the surgery of trauma practice management guideline. J Trauma Acute Care Surg 2012;73(5 Suppl 4):S294-300.

2. Rowell SE, Biffl WL, Brasel K, Moore EE, Albrecht RA, DeMoya M, et al. Western trauma association critical decisions in trauma: management of adult blunt splenic trauma-2016 updates. J Trauma Acute Care Surg 2017;82:787-93. 